\title{
A prospective randomized controlled double-blind trial to assess the effects of dexmedetomidine during cleft palate surgery
}

\author{
Priyanka Surana, Devangi A. Parikh, Geeta A. Patkar, and \\ Bharati A. Tendolkar \\ Department of Anesthesiology, Lokmanya Tilak Municipal Medical College and Lokmanya Tilak Municipal \\ General Hospital, Mumbai, India
}

\begin{abstract}
Background: We investigated whether the intraoperative administration of dexmedetomidine would attenuate the profound sympathoadrenal response associated with cleft palate (CP) surgery.

Methods: Sixty children aged 6 months to 12 years undergoing CP surgery under general anesthesia were randomly assigned to the control (C) or dexmedetomidine (D) groups. Group C received benzodiazepine $(0.05 \mathrm{mg} / \mathrm{kg}$ midazolam followed by infusion of normal saline) fentanyl isoflurane anesthesia, and Group D received dexmedetomidine (loading $1 \mu \mathrm{g} / \mathrm{kg}$ followed by infusion of $0.5 \mu \mathrm{g} / \mathrm{kg} / \mathrm{h}$ ) fentanyl isoflurane anesthesia. Heart rate (HR), mean blood pressure (MBP), intraoperative fentanyl and isoflurane requirements, recovery scores, emergence agitation, pain scores, time and requirement of rescue analgesic, and surgeon satisfaction were noted.

Results: Intraoperative HR and MBP in Group D were significantly lower than the corresponding values in Group C $(\mathrm{P}<$ 0.001). HR decreased up to $16 \%$ in Group D. By contrast, HR increased up to $20 \%$ in Group C. Group D had comparable MBP to its baseline, whereas Group C had higher MBP until extubation $(\mathrm{P}=0.015)$. Two children in Group D developed bradycardia and hypotension, which was successfully treated. The fentanyl and isoflurane requirements decreased by $43 \%$ and $30 \%$, respectively, in Group D patients compared to those in Group C $(\mathrm{P}<0.001)$. Group D had lower pain scores and less emergence agitation $(\mathrm{P}<0.001)$. Time until requirement of first rescue analgesic was longer in Group D than that in Group C $(\mathrm{P}<0.001)$. Surgeon satisfaction was higher in Group D than that in Group C.

Conclusions: Intravenous dexmedetomidine during CP surgery attenuated hemodynamic responses with excellent surgeon satisfaction. Close monitoring of hemodynamics is recommended.
\end{abstract}

Key Words: Anesthesia, Cleft palate, Dexmedetomidine, Hemodynamics, Pediatric, Surgery.

Corresponding author: Priyanka Surana, M.D.

Department of Anesthesiology, Lokmanya Tilak Municipal Medical College and Lokmanya Tilak Municipal General Hospital, Sulochana Shetty road, Sion, Mumbai-400020, Maharashtra, India

Tel: 91-9619660996, Fax: 91-22 24044154

Email: drpriyankasurana@yahoo.com

ORCID: https://orcid.org/0000-0002-2648-837X

Received: December 23, 2016. Revised: April 11, 2017. Accepted: April 18, 2017.

Korean J Anesthesiol 2017 December 70(6): 633-641

https://doi.org/10.4097/kjae.2017.70.6.633

(c) This is an open-access article distributed under the terms of the Creative Commons Attribution Non-Commercial License (http://creativecommons.org/ licenses/by-nc/4.0/), which permits unrestricted non-commercial use, distribution, and reproduction in any medium, provided the original work is properly cited. 


\section{Introduction}

Cleft palate (CP) surgery aims to correct an anatomically defective palate to augment normal dent-alveolar development, leading to effective palatal function [1]. The surgery involves dissecting the hard and soft palates, resulting in profound sympathetic stimulation leading to hypertension, tachycardia [2], and bleeding. In addition, postoperative recovery and pain relief are important to prevent airway obstruction and oozing from the surgical site $[3,4]$. High-dose opioids with inhalationals are commonly used to block the autonomic response [2]. However, this may be associated with residual sedation and respiratory depression. Surgical infiltration with a local anesthetic and a vasoconstrictor $[5,6]$ partially blocks the profound autonomic response intraoperatively, but does not provide long-lasting postoperative pain relief.

Dexmedetomidine is a selective $\alpha_{2}$ receptor agonist with sedative, sympatholytic, analgesic, opioid, and anesthetic-sparing properties without producing significant respiratory depression. It reduces the stress response to surgery and ensures a stable hemodynamic state $[7,8]$. We hypothesized that dexmedetomidine might be useful when repairing the $\mathrm{CP}$, because the residual depressant effects of opioids are particularly harmful in this setting [3].

This randomized, double-blind study evaluated dexmedetomidine in patients undergoing CP surgery, and compared it to our conventional benzodiazepine opioid inhalational technique. The primary endpoint was attenuation of the intraoperative hemodynamic response. Intraoperative inhalational and opioid requirements, emergence agitation, postoperative pain score, and surgeon satisfaction score were the secondary endpoints.

\section{Materials and Methods}

This prospective, randomized controlled, double-blind study was undertaken from January 2013 to June 2014 after institutional ethics committee approval. Sixty patients of either sex, American Society of Anesthesiologists (ASA) grade 1, and age between 6 months and 12 years posted for CP surgery under general anesthesia were included. Patients with ASA grade 2 and above, who were unwilling to consent, or who had an allergy to $\alpha_{2}$ adrenergic agonist were excluded. All of the children were examined the day before surgery and thoroughly investigated according to the institute protocol. Written informed consent from the parents and assent from children $>7$ years was obtained. Anesthesiologist A enrolled the patients and randomized them into two groups using a computer-generated randomized chart to receive general anesthesia with either the conventional benzodiazepine opioid inhalational (Group C) or dexmedetomidine opioid inhalational (Group D) technique intraoperatively. Anes- thesiologist A was not involved in the study. The random group assignments were enclosed in a sealed opaque envelope to ensure that the allocation sequence was concealed. Anesthesiologist $\mathrm{B}$, who was also not involved in the study, opened the sealed envelope and prepared the drug solution according to randomization. The anesthesiologist conducting the case, the surgeons, the patients, and the anesthesiologist in the post-anesthesia care unit (PACU) were all blinded to the group assignments. Data was recorded by a blinded observer. Two $20 \mathrm{ml}$ syringes, labeled "loading" and "maintenance," were given to each patient. Group C received $0.05 \mathrm{mg} / \mathrm{kg}$ midazolam and Group D patients received $1 \mu \mathrm{g} / \mathrm{kg}$ dexmedetomidine in their respective loading syringes diluted in $20 \mathrm{ml}$ normal saline (NS). Group C received NS and Group D received $1 \mu \mathrm{g} / \mathrm{ml}$ dexmedetomidine in their respective maintenance syringes. A benzodiazepine infusion was started in the control group to maintain blinding with the study group. The benzodiazepine was omitted from study Group D, because in a pilot study of five cases, we noted bradycardia with the benzodiazepine combination, requiring atropine in all cases. The results of the pilot cases are not included in this study.

All the children were kept fasting for $6 \mathrm{~h}$. No premedication was administered, and the child was taken to the operation theatre. Routine noninvasive monitoring included parameters such as heart rate (HR), systolic blood pressure, diastolic blood pressure, mean blood pressure (MBP), oxygen saturation $\left(\mathrm{SpO}_{2}\right)$ end-tidal carbon dioxide $\left(\mathrm{ETCO}_{2}\right)$, and end-tidal inhalational concentration using a multigas analyzer monitor (B40; GE Medical Systems, Solingen, Germany). The child was given anesthesia with $100 \%$ oxygen and $8 \%$ sevoflurane and an intravenous (IV) line was secured followed by injection of $0.004 \mathrm{mg} / \mathrm{kg}$ IV glycopyrrolate and $2 \mu \mathrm{g} / \mathrm{kg}$ fentanyl. After intermittent positive pressure ventilation was confirmed, $1.5 \mathrm{mg} / \mathrm{kg}$ IV suxamethonium was injected. The child was intubated with an appropriate sized uncuffed Ring-Adair-Elwyn south pole tube, and a throat pack was placed. Ventilation was performed with a standard ventilator equipped with a pediatric circle circuit (DatexOhmeda, Helsinki, Finland), tidal volume of $6-8 \mathrm{ml} / \mathrm{kg}$, and a rate adjusted to maintain the $\mathrm{ETCO}_{2}$ concentration between 32 and $35 \mathrm{mmHg}$ at a total gas flow of $2 \mathrm{~L} / \mathrm{min}$. General anesthesia was maintained with $50 \% \mathrm{O}_{2}+50 \% \mathrm{~N}_{2} \mathrm{O}$ with vecuronium and isoflurane, which was titrated according to the hemodynamic parameters. Isoflurane was started to achieve an end-tidal concentration of $0.6 \%$ in both groups. Dexamethasone $(0.2 \mathrm{mg} /$ $\mathrm{kg}$ ) was given as an antiemetic and to reduce airway edema. Post-intubation, Group C $(\mathrm{n}=30)$ received $0.05 \mathrm{mg} / \mathrm{kg}$ IV midazolam diluted in $20 \mathrm{ml} \mathrm{NS}$ as a loading dose over $10 \mathrm{~min}$ followed by a maintenance infusion of normal saline at $0.5 \mathrm{ml} / \mathrm{kg} /$ $\mathrm{h}$, and Group D $(\mathrm{n}=30)$ received $1 \mu \mathrm{g} / \mathrm{kg}$ IV dexmedetomidine diluted in $20 \mathrm{ml} \mathrm{NS}$ as a loading dose over $10 \mathrm{~min}$ followed by a maintenance infusion of $0.5 \mu \mathrm{g} / \mathrm{kg} / \mathrm{h}$. Rectal diclofenac sodium 
suppository ( $2 \mathrm{mg} / \mathrm{kg}$ ) was inserted into children $>1$ year for postoperative analgesia, and paracetamol suppository $(30 \mathrm{mg} /$ $\mathrm{kg}$ ) was used in children $<1$ year in view of immature metabolism and clearance in the latter. The surgical incision was started 10 min after the surgeon had infiltrated the surgical site with a solution containing $1: 200,000$ epinephrine as per weight of the child.

Hemodynamic parameters (i.e., HR and MBP) were noted at pre-induction (T0), pre-intubation (T1), post-intubation and start of infusion (T2), post-epinephrine infiltration (T3), start of surgical dissection and every 15 min thereafter (T4-T10), end of surgery (T11), extubation (T12), and at $0.5,1$, and $2 \mathrm{~h}$ after shifting to PACU (T13-T15). $\mathrm{SpO}_{2}, \mathrm{ETCO}_{2}$, end-tidal isoflurane concentration, rectal temperature, and blood loss were monitored. Body temperature was stabilized using a warming mattress. The inspiratory concentration of isoflurane was adjusted in increasing or decreasing values of $0.2 \%$ up to a maximum of $1 \%$ end-tidal concentration as judged by the increase or decrease in hemodynamics within $20 \%$ from baseline values. An additional $1 \mu \mathrm{g} / \mathrm{kg}$ dose of fentanyl was repeated whenever the end-tidal concentration reached $1 \%$, and total fentanyl required throughout surgery was noted. All of the patients received IV Ringers lactate with $2.5 \%$ dextrose as per the Holliday Segar formula for starvation and maintenance. The maintenance infusion of dexmedetomidine and NS in their respective groups was stopped just before the last suture was applied. Isoflurane was stopped 15 min before completion of the surgery and $\mathrm{N}_{2} \mathrm{O}$ was discontinued after the last suture was applied.

At the end of surgery, the urinary bladder of all patients was emptied with a sterile catheter. Patients were reversed with 0.05 $\mathrm{mg} / \mathrm{kg}$ IV neostigmine and $0.008 \mathrm{mg} / \mathrm{kg}$ glycopyrrolate, and extubated after meeting the standard extubation criteria. Time taken from stopping the infusion until opening of the eyes on command was noted. The time taken from stopping the infusion until extubation was also noted. Complications at extubation such as airway obstruction or desaturation, if any, were also noted. Then the patient was shifted to the PACU for postoperative monitoring. The PACU emergence agitation score (Appendix 1) was noted on the 0-4 point Watcha Emergence Agitation Scale [9]. Pain was assessed with the Faces, Legs, Activity, Cry and Consolability (FLACC) Behavioral Pain Assessment Scale pain score [10] (Appendix 2) and time to requirement of first postoperative analgesic was noted. If the FLACC pain score was $\geq$ 4 , then $1 \mu \mathrm{g} / \mathrm{kg}$ IV fentanyl was given as a rescue analgesic. The number of patients requiring rescue fentanyl in both groups was noted. The children were shifted to the ward once the Stewards Recovery Score [11] (Appendix 3) was $>6$ or after $2 \mathrm{~h}$, whichever was later. In the surgical ward, children $<1$ year received a paracetamol suppository and children $>1$ year received a diclofenac suppository three times/day as per conventional protocol. Surgeons satisfaction score (0-10), based on bleeding from the surgical field, was noted at the end of surgery.

Hypertension and tachycardia were diagnosed intraoperatively if there was $>20 \%$ rise in MBP or HR above baseline on two or more readings in 2-3 min, which was managed by increasing isoflurane up to the maximum of $1 \%$ end-tidal concentration, followed by $1 \mu \mathrm{g} / \mathrm{kg}$ IV fentanyl if not controlled. Hypotension was defined as a reduction in SBP as per age-specific guidelines [12] and was corrected with IV fluids, stopping infusions, and administering IV ephedrine, if required. Bradycardia

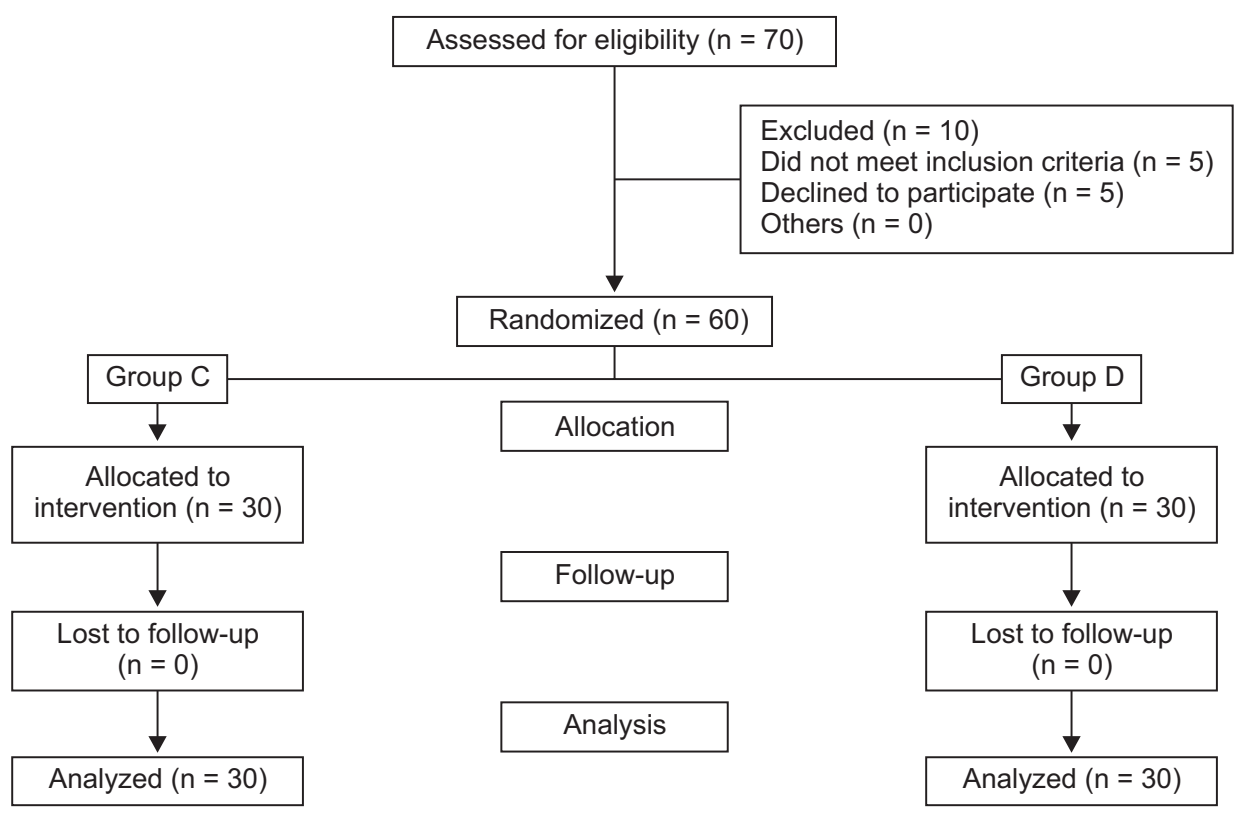

Fig. 1. CONSORT flow diagram. Sixty children were randomized and all of them completed the study. 
was similarly defined as a reduction in HR as per age-specific guidelines [12] and was managed by stopping infusions and administering $0.01 \mathrm{mg} / \mathrm{kg}$ atropine. Postoperative desaturation, nausea, and vomiting were also noted.

Data analyses were performed using SPSS ver. 16.0 software (SPSS Inc., Chicago, IL, USA). The normality of the data was tested using the Shapiro-Wilk test. Continuous data are expressed as mean $\pm \mathrm{SD}$, and qualitative data are expressed as median and interquartile range. The unpaired $t$-test was used for intergroup comparisons between HR and MBP at each time point. Repeated-measures analysis of variance (RMANOVA) was used for within-group comparisons of HR and MBP. The data did not satisfy the assumption of sphericity as tested by the Mauchly's test; therefore, the Greenhouse-Geisser correction was applied. In the case of a significant intragroup difference by RMANOVA, post-hoc pairwise comparisons were made using Bonferroni's adjustment. Data that were not normally distributed were compared using the Mann-Whitney $U$ test. Categorical data were analyzed using the chi-square test and expressed as frequencies. $\mathrm{P}$ values $<0.05$ were considered statistically significant. Power analyses were based on the primary endpoint (i.e., control of intraoperative hemodynamics). In a previous study, the reported difference in HR was $14 \%$ in a dexmedetomidinetreated group in response to tracheal intubation [13]. We considered an intergroup difference in HR of at least $25 \%$ to be clinically relevant. Assuming a two-sided type I error protection of 0.05 and a power of $0.80,29$ patients were required in each group to reveal a clinically significant difference. This number

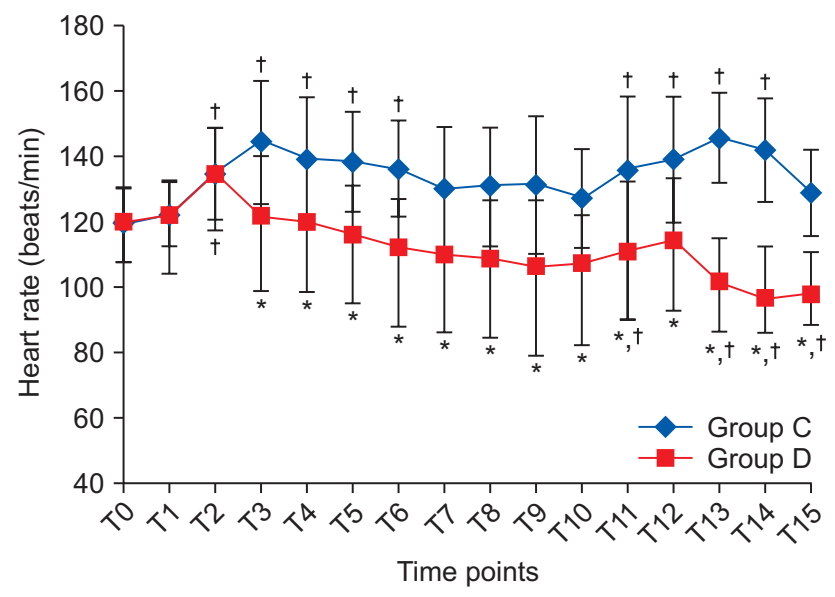

Fig. 2. Changes in heart rate at different time points. Data are expressed as mean $\pm \mathrm{SD} .{ }^{*} \mathrm{P}<0.05$ compared to Group $\mathrm{C},{ }^{\dagger}$ Post-hoc Bonferroni test $(\mathrm{P}<0.05)$ compared to T0 within each group. T0: Preinduction, T1: preintubation, T2: post-intubation and start of infusion, T3: post epinephrine infiltration, T4-T10: start of surgical dissection and every 15 min thereafter, T11: end of surgery, T12: extubation, T13-15: 0.5, 1, and $2 \mathrm{~h}$ after shifting to post-anesthesia care unit. was increased to 30 patients per group.

\section{Results}

Sixty pediatric patients were enrolled. All the patients underwent their planned surgical procedure and received their allocated mode of anesthesia. No assigned patients dropped out of the study (Fig. 1). Clinical characteristics, demographic data, and duration and type of surgery were comparable between the two groups (Table 1). Baseline HR and MBP measurements were comparable between the groups. $\mathrm{HR}$ and MBP were significantly different between the groups at almost all of the time intervals throughout surgery (Figs. 2 and 3). Group C patients showed a significant rise in HR $(6-20 \%)(\mathrm{P}<0.005)$ from the corresponding baseline value nearly throughout the surgery (Fig.

Table 1. Patient Characteristics and Surgical Data

\begin{tabular}{lcc}
\hline & $\begin{array}{c}\text { Group C } \\
(\mathrm{n}=30)\end{array}$ & $\begin{array}{c}\text { Group D } \\
(\mathrm{n}=30)\end{array}$ \\
\hline Age (months) & $14.5(9-31.5)$ & $22(10-42.75)$ \\
Sex $(\mathrm{M} / \mathrm{F})$ & $15 / 15$ & $15 / 15$ \\
Weight $(\mathrm{kg})$ & $10.3 \pm 5.6$ & $11.4 \pm 5.8$ \\
Duration of surgery $(\mathrm{min})$ & $240 \pm 20.5$ & $234 \pm 19.5$ \\
Surgery type (I/II/III/IV) & $3 / 12 / 3 / 12$ & $3 / 12 / 6 / 9$ \\
\hline
\end{tabular}

Data are expressed as mean $\pm \mathrm{SD}$, median (IQR), or number (\%). Group C: control group, Group D: dexmedetomidine group, I: anterior palate, II: primary palate repair, III: palatoplasty, IV: secondary palate repair. IQR: interquartile range.

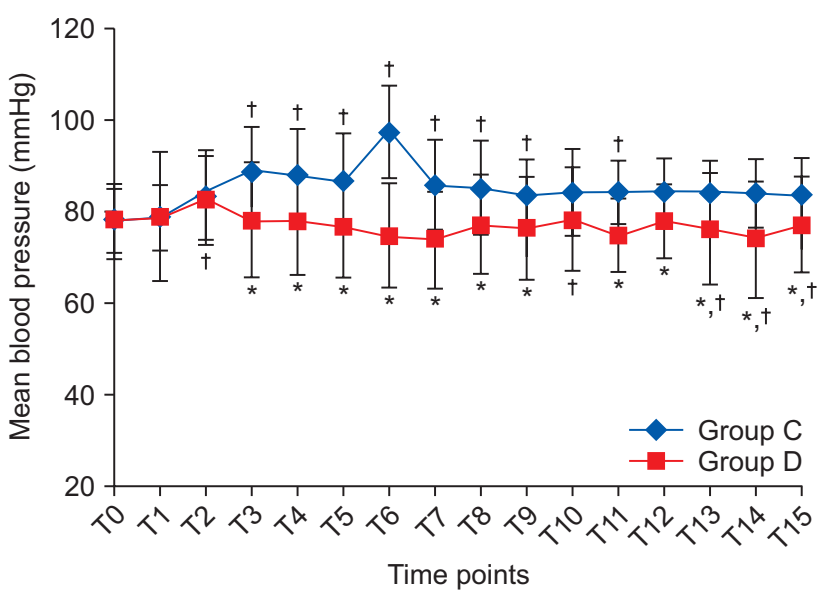

Fig. 3. Changes in mean blood pressure at different time points. Data are expressed as mean $\pm \mathrm{SD} .{ }^{*} \mathrm{P}<0.05$ compared to Group $\mathrm{C}$, ${ }^{\dagger}$ Posthoc Bonferroni test $(\mathrm{P}<0.05)$ compared to $\mathrm{T} 0$ within each group. T0: Preinduction, T1: preintubation, T2: post-intubation and start of infusion, T3: post-epinephrine infiltration, T4-T10: start of surgical dissection and every 15 min thereafter, T11: end of surgery, T12: extubation, T13-15: 0.5, 1 , and $2 \mathrm{~h}$ after shifting to post-anesthesia care unit. 
2). By contrast, Group D patients had a lower HR compared to its baseline value, which was not significant at any time point, except T10 and in the PACU, where it was significant but within age-acceptable limits (Fig. 2). Group C patients showed a significant rise in MBP from baseline until extubation (T12) $(\mathrm{P}=0.015$, Fig. 3). In Group D, MBP was comparable with its corresponding baseline value at all of the time points (Fig. 3). Two patients in the dexmedetomidine group developed bradycardia and hypotension intraoperatively, which was managed by stopping the dexmedetomidine infusion, infusing fluids, and injecting 0.01 $\mathrm{mg} / \mathrm{kg}$ atropine. The dexmedetomidine infusion was resumed after treating the bradycardia. No vasopressors were required to treat hypotension. $\mathrm{SpO}_{2}, \mathrm{ETCO}_{2}$, temperature, blood loss, and urine output were comparable between the groups.

The requirements for opioid and inhalational agents to maintain hemodynamics within $20 \%$ of baseline values were higher in Group C than those in Group D (Table 2). Time to eye opening and extubation were comparable between the groups. Children in Group D had significantly lower pain scores in the PACU than those in the control group $(\mathrm{P}<0.0005)$ (Table 3$)$. Time to first postoperative rescue analgesic was significantly longer in group D than that in the group C (Table 4). Significantly more children required rescue fentanyl in Group $C$ than those in Group D ( $\mathrm{P}=0.001)$. Children in Group D had lower emergence agitation scores than those in Group C, and children in Group D were calm and quiet in the PACU. Satisfaction with the surgeon with respect to bleeding at the surgical site was higher in Group D than in Group C. No patient in either group experienced postoperative nausea, vomiting, or shivering. There were no signs of respiratory compromise in either group. Re-

Table 2. Anesthesia Characteristics

\begin{tabular}{lccc}
\hline \multicolumn{1}{c}{ Study variables } & $\begin{array}{c}\text { Group C } \\
(\mathrm{n}=30)\end{array}$ & $\begin{array}{c}\text { Group D } \\
(\mathrm{n}=30)\end{array}$ & P value \\
\hline Fentanyl requirement $(\mu \mathrm{g} / \mathrm{kg})$ & $5.3 \pm 0.95(4.9-5.6)$ & $2.3 \pm 1.4(1.8-2.8)$ & $0.001^{*}$ \\
Inhalational requirement $(\mathrm{ET} \%)$ & $1.03 \pm 0.11(0.99-1.07)$ & $0.73 \pm 0.08(0.7-0.76)$ & $0.001^{*}$ \\
Time to eye opening (min) & $13.33 \pm 10.73(9.4-17.1)$ & $10.03 \pm 4.55(8.4-11.6)$ & 0.100 \\
Time to extubation $(\mathrm{min})$ & $17.73 \pm 10.73(13.8-21.5)$ & $13.83 \pm 4.20(12.3-15.3)$ & 0.068
\end{tabular}

Data are expressed as mean \pm SD and 95\% CI. Group C: control group, Group D: dexmedetomidine group. ${ }^{*} \mathrm{P}<0.05$ compared to Group C. ET: end tidal.

Table 3. Faces, Legs, Activity, Cry and Consolability (FLACC) Behavioral Pain Assessment Scale (0-10) Recorded in the Post-anesthesia Care Unit (PACU)

\begin{tabular}{clll}
\hline Time after shifting to PACU & Group C & Group D & P value \\
\hline 15 min & $5(4-5)$ & $0(0-1)$ & $<0.001^{*}$ \\
$30 \mathrm{~min}$ & $5(4-5)$ & $0(0-1)$ & $<0.001^{*}$ \\
$45 \mathrm{~min}$ & $5(4.75-6)$ & $0(0-1)$ & $<0.001^{*}$ \\
$60 \mathrm{~min}$ & $5(5-6)$ & $0(0-1.25)$ & $<0.001^{*}$ \\
$75 \mathrm{~min}$ & $6(5-6)$ & $1(0-1.25)$ & $<0.001^{*}$ \\
$90 \mathrm{~min}$ & $6(5.75-6)$ & $1(1-2)$ & $<0.001^{*}$ \\
$105 \mathrm{~min}$ & $6(5.75-6)$ & $1(1-2)$ & $<0.001^{*}$ \\
$120 \mathrm{~min}$ & $6.5(6-7)$ & $2(2-2.25)$ & $<0.001^{*}$ \\
\hline
\end{tabular}

Data are expressed as median (interquartile range). Group C: control group, Group D: dexmedetomidine group. ${ }^{*} \mathrm{P}<0.05$.

Table 4. Emergence Agitation, Surgeon Satisfaction Score, and Time to Postoperative Rescue Analgesics

\begin{tabular}{|c|c|c|c|}
\hline & $\begin{array}{l}\text { Group C } \\
(\mathrm{n}=30)\end{array}$ & $\begin{array}{l}\text { Group D } \\
(\mathrm{n}=30)\end{array}$ & $P$ value \\
\hline Emergence agitation score (1-4) & $3(3-3)$ & $1(1-2)$ & $0.001^{*}$ \\
\hline Time until postoperative rescue analgesic & $57.67 \pm 36.07(44.7-70.5)$ & $141.30 \pm 81.91(112-170.6)$ & $0.001^{*}$ \\
\hline Number of children requiring rescue fentanyl $(\mathrm{Y} / \mathrm{N})$ & $20 / 10$ & $7 / 23$ & $0.001^{*}$ \\
\hline Surgeon satisfaction score $(1-10)$ & $7.5(7-8)$ & $10(9-10)$ & $0.001^{*}$ \\
\hline $\begin{array}{l}\text { Complications } \\
\text { (hypotension/bradycardia/PONV/desaturation/delayed emergence) }\end{array}$ & $(0 / 0 / 0 / 0 / 0)$ & $(2 / 2 / 0 / 0 / 0)$ & 0.900 \\
\hline
\end{tabular}

Data are expressed as mean \pm SD and $95 \%$ CI or median (IQR). Group C: control group, Group D: dexmedetomidine group. ${ }^{*} \mathrm{P}<0.05 . \mathrm{PONV}$ : postoperative nausea and vomiting, IQR: interquartile range. 
covery scores were comparable, and all of the children met the PACU discharge criteria within 45 min of arrival. However, due to the nature of the surgery and pediatric age group, all children were discharged from PACU after $2 \mathrm{~h}$. No major complications were observed in either group intraoperatively or in the PACU.

\section{Discussion}

The dexmedetomidine opioid inhalational technique provided efficient control of intraoperative hemodynamic responses with an excellent surgical field, less requirement for opioids and inhalationals, lower postoperative pain scores, calm and less agitated children, and superior surgeon satisfaction.

CP surgeries are associated with immense autonomic stimulation necessitating high doses of IV opioids [14]. Postoperative airway obstruction and respiratory depression must be managed, the causes of which are a critical reduction in the size of a previous tenuous airway, postoperative bleeding, and excessive sedation from opioids [2,3]. The incidence of airway compromise can reach up to $18 \%$ in isolated CP cases [4]. In view of intense postoperative pain, adequate pain relief is required, as vigorous crying may cause wound dehiscence resulting in tardy recovery and late hospital discharge [15].

Short-acting opioids ( $3 \mu \mathrm{g} / \mathrm{kg}$ fentanyl for a $1 \mathrm{~h}$ procedure) in association with an inhalational agent can effectively block a major part of the autonomic response in patients who undergo a CP surgery [2]. However, IV morphine is also required with all short-acting opioids during the initial postoperative period, which requires intense monitoring. Surgical infiltration and various nerve blocks are used to repress the hemodynamic effects and to achieve adequate postoperative pain relief $[5,6,16]$. However, there is no single effective block for CP surgeries and a multimodal approach to pain management has been recommended [17]. Despite the lack of FDA labeling for pediatric use, dexmedetomidine has been increasingly used in these patients over recent years $[7,8,18]$. In our study, we chose dexmedetomidine, as it stabilizes hemodynamics with minimal respiratory depression [18] and also plays a role in postoperative analgesia [7].

A pharmacokinetic study of IV dexmedetomidine in children $<11$ years [19] concluded that children $<2$ years need larger loading doses $(2 \mu \mathrm{g} / \mathrm{kg})$ to reach a certain plasma concentration, in view of the larger volume of distribution and similar maintenance rates as adults. However, in our vulnerable group of patients aged 6 months to 12 years, we chose a uniform loading dose of $1 \mu \mathrm{g} / \mathrm{kg}$ considering that dexmedetomidine does have a propensity to cause bradycardia and hypotension and also because we were using volatile anesthetics and opioids concurrently. On the other hand, Group C patients received a single dose of midazolam at induction, which was given as an infusion over 10 min, to maintain blinding with Group D. The main reason for not giving a maintenance infusion of midazolam is that opioids and benzodiazepines are synergistic and can cause respiratory depression. CP surgery is known to have complications of laryngeal edema and postoperative respiratory obstruction, which could be detrimental to this vulnerable age group. A continuous midazolam infusion was not administered to avoid the residual effects of the benzodiazepine at the time of extubation.

The lower HR and MBP in Group D compared to that in Group C is explained by markedly decreased sympathetic activity [20]. These effects could not be studied at intubation, as it was not possible to start infusions prior to induction in the pediatric patients. No sympathetic response was detected in Group $\mathrm{D}$ during the intraoperative dissection phase (approximately $100 \mathrm{~min}$ ), at extubation, or postoperatively in the PACU. This was in contrast to Group C, which had significant tachycardia. This finding is similar to other studies where dexmedetomidine was used during pediatric laparoscopic procedures [21] and neonatal laparotomies [22], in which stable hemodynamics were maintained even in periods of heightened surgical stimulation. Studies evaluating remifentanil during CP surgeries [14,23,24] suggest that hemodynamic stability is achieved in the remifentanil group in view of the lower HR. However, in our study, two patients developed bradycardia and hypotension that responded to atropine, temporarily stopping the dexmedetomidine infusion and infusing fluids. Administering atropine caused tachycardia, and the dexmedetomidine infusion was restarted as the tachycardia led to increased bleeding in the surgical field. However, considering the propensity of dexmedetomidine to cause bradycardia, it would have been ideal to not restart the infusion in terms of patient safety. This could be a limitation of the study, as these two patients were not excluded from the final analysis.

The intraoperative requirements for fentanyl and isoflurane decreased markedly by $43 \%$ and $30 \%$, respectively, in Group $\mathrm{D}$ patients, which is consistent with a previous study [8]. The decreased requirement for volatile anesthetics and opioids are possibly mediated by the effects of dexmedetomidine on preand post-synaptic a-receptor activation in the central nervous system [20]. Postoperative pain scores were lower and time to first rescue analgesic was longer in Group D than in Group C, probably because adrenoreceptors inhibited the release of norepinephrine and terminated the propagation of pain signals [20]. Although the cause of emergence agitation is multifactorial, dexmedetomidine probably decreased emergence agitation compared to that in Group C in view of its sedative, analgesic, and anesthetic-sparing properties [25].

$\mathrm{Xu}$ et al. [26] prospectively evaluated intravenous dexmedetomidine for postoperative agitation and analgesia during $\mathrm{CP}$ surgeries in four different doses, and Kayyal et al. [15] retrospectively evaluated dexmedetomidine compared to ketamine for postoperative pain relief during CP surgeries. Both authors 
concluded that the dexmedetomidine group had lower pain scores. However, intraoperative hemodynamics in response to a surgical stimulus and the surgical field has not been commented upon. A recent meta-analysis [27] evaluated dexmedetomidine for postoperative pain, opioid consumption, and postoperative nausea and vomiting in pediatric patients. The authors stated that a limitation of the meta-analysis was that the effects of intraoperative dexmedetomidine on hemodynamics in pediatric patients have not been evaluated in view of the absence of an exhaustive search for articles displaying this outcome, and the different dosing regimens used by different authors. Thus, the current study may add information to the existing literature in terms of the effects of dexmedetomidine on intraoperative hemodynamics as the primary outcome measure. A recent editorial suggested the need for further studies to examine dexmedetomidine in various surgical settings [28].

Our study demonstrated a superior surgeon satisfaction score in Group D compared to that in Group C with respect to bleeding in the surgical field. The lower HR could be attributed to this finding, as HR is an important predictor of the surgical field [29]. Recovery times were also comparable in both groups, and we did not see delayed extubation or discharge in Group D contrary to other studies [26]. This finding may have been related to the maintenance infusion of $0.5 \mu \mathrm{g} / \mathrm{kg} / \mathrm{h}$ and lower opioid requirement in Group D. Moreover, we omitted midazolam in Group D patients.

A possible limitation of our study is that we did not use bispectral index (BIS)-guided monitoring to measure the depth of anesthesia due to a lack of availability at our institute. Estimating anesthesia depth is difficult, as dexmedetomidine increases hemodynamic stability. A BIS-guided evaluation study comparing dexmedetomidine with midazolam during opioid inhalational-based general anesthesia concluded that dexmedetomidine maintains BIS levels comparable with those of midazolam with a significantly lower sevoflurane requirement [30]. In the current study, BIS monitoring would have definitely been more objective to determine anesthetic depth. In addition, it would have been worthwhile to compare dexmedetomidine with already studied remifentanil in CP surgeries [14,23,24] which was not done due to a lack of availability.

In summary, a $1 \mu \mathrm{g} / \mathrm{kg}$ loading dose of dexmedetomidine followed by a maintenance infusion dose of $0.5 \mu \mathrm{g} / \mathrm{kg} / \mathrm{h}$ attenuated the towering autonomic response related with CP surgery, thereby imparting hemodynamic stability intraoperatively, on emergence and postoperatively. The decreased opioid and volatile anesthetic requirements with reduced emergence agitation, postoperative pain, and better surgeon satisfaction may make it a suitable agent for use in CP surgery. However, hemodynamics need to be closely monitored.

\section{ORCID}

Priyanka Surana, https://orcid.org/0000-0002-2648-837X

Geeta A. Patkar, https://orcid.org/0000-0001-6776-8506

Bharati A. Tendolkar, https://orcid.org/0000-0002-5256-7178

\section{References}

1. Somerville N, Fenlon S. Anaesthesia for cleft lip and palate surgery. Contin Educ Anaesth Crit Care Pain 2005; 5: 76-9.

2. Tremlett M. Anaesthesia for cleft lip and palate surgery. Curr Anaesth Crit Care 2004; 15: 309-16.

3. Kulkarni KR, Patil MR, Shirke AM, Jadhav SB. Perioperative respiratory complications in cleft lip and palate repairs: an audit of 1000 cases under 'Smile Train Project'. Indian J Anaesth 2013; 57: 562-8.

4. Liau JY, Sadove AM, van Aalst JA. An evidence-based approach to cleft palate repair. Plast Reconstr Surg 2010; 126: $2216-21$.

5. Muthukumar M, Arya VK, Mathew PJ, Sharma RK. Comparison of haemodynamic responses following different concentrations of adrenaline with and without lignocaine for surgical field infiltration during cleft lip and cleft palate surgery in children. Anaesth Intensive Care 2012; 40: 114-9.

6. Kinsella CR Jr, Castillo N, Naran S, Smith DM, DeCesare GE, Cladis FP, et al. Intraoperative high-dose epinephrine infiltration in cleft palate repair. J Craniofac Surg 2014; 25: 140-2.

7. Mason KP, Lerman J. Review article: dexmedetomidine in children: current knowledge and future applications. Anesth Analg 2011; 113: $1129-42$.

8. Mahmoud M, Mason KP. Dexmedetomidine: review, update, and future considerations of paediatric perioperative and periprocedural applications and limitations. Br J Anaesth 2015; 115: 171-82.

9. Reduque LL, Verghese ST. Paediatric emergence delirium. Contin Educ Anaesth Crit Care Pain 2013; 13: 39-41.

10. Merkel SI, Voepel-Lewis T, Shayevitz JR, Malviya S. The FLACC: a behavioral scale for scoring postoperative pain in young children. Pediatr Nurs 1997; 23: 293-7.

11. Steward DJ. A simplified scoring system for the post-operative recovery room. Can Anaesth Soc J 1975; 22: 111-3.

12. de Caen AR, Berg MD, Chameides L, Gooden CK, Hickey RW, Scott HF, et al. Part 12: pediatric advanced life support: 2015 American Heart Association guidelines update for cardiopulmonary resuscitation and emergency cardiovascular care. Circulation 2015; 132(18 Suppl 
2): S526-42.

13. Keniya VM, Ladi S, Naphade R. Dexmedetomidine attenuates sympathoadrenal response to tracheal intubation and reduces perioperative anaesthetic requirement. Indian J Anaesth 2011; 55: 352-7.

14. Roulleau P, Gall O, Desjeux L, Dagher C, Murat I. Remifentanil infusion for cleft palate surgery in young infants. Paediatr Anaesth 2003; 13: 701-7.

15. Kayyal TA, Wolfswinkel EM, Weathers WM, Capehart SJ, Monson LA, Buchanan EP, et al. Treatment effects of dexmedetomidine and ketamine on postoperative analgesia after cleft palate repair. Craniomaxillofac Trauma Reconstr 2014; 7: 131-8.

16. Chiono J, Raux O, Bringuier S, Sola C, Bigorre M, Capdevila X, et al. Bilateral suprazygomatic maxillary nerve block for cleft palate repair in children: a prospective, randomized, double-blind study versus placebo. Anesthesiology 2014; 120: 1362-9.

17. Reena, Bandyopadhyay KH, Paul A. Postoperative analgesia for cleft lip and palate repair in children. J Anaesthesiol Clin Pharmacol 2016; 32: 5-11.

18. Kim SK, Song MH, Lee IJ, Lee JH, Choi IC. Dexmedetomidine for sedation in pediatric patients who received more than 20 sessions of radiation therapy: two cases report. Korean J Anesthesiol 2016; 69: 627-31.

19. Vilo S, Rautiainen P, Kaisti K, Aantaa R, Scheinin M, Manner T, et al. Pharmacokinetics of intravenous dexmedetomidine in children under $11 \mathrm{yr}$ of age. Br J Anaesth 2008; 100: 697-700.

20. Chen JH, Yu YQ, Chu HJ, Han H, Cao Y, Dai ZP. Effects of dexmedetomidine on postoperative recovery profile after sevoflurane anesthesia in pediatric patients: a meta-analysis. J Anesth Clin Res 2013; 4: 369.

21. Smania MC, Piva JP, Garcia PC. Dexmedetomidine in anesthesia of children submitted to videolaparoscopic appendectomy: a double-blind, randomized and placebo-controlled study. Rev Assoc Med Bras (1992) 2008; 54: 308-13.

22. Dilek O, Yasemin G, Atci M. Preliminary experience with dexmedetomidine in neonatal anesthesia. J Anaesthesiol Clin Pharmacol 2011; 27: 17-22.

23. Steinmetz J, Holm-Knudsen R, Sørensen MK, Eriksen K, Rasmussen LS. Hemodynamic differences between propofol-remifentanil and sevoflurane anesthesia for repair of cleft lip and palate in infants. Paediatr Anaesth 2007; 17: 32-7.

24. Gai CA, Zhu ZR, Hu ZY, Jiang YL. Clinical comparison of sevoflurane and propofol anesthesia with propofol and remifentanil anesthesia for children with cleft lip and palate repair surgery. Zhonghua Yi Xue Za Zhi 2013; 93: 1819-21.

25. Hauber JA, Davis PJ, Bendel LP, Martyn SV, McCarthy DL, Evans MC, et al. Dexmedetomidine as a rapid bolus for treatment and prophylactic prevention of emergence agitation in anesthetized children. Anesth Analg 2015; 121: 1308-15.

26. Xu YY, Song XR, Lin ZM, Zhang GQ, Zhang N. Effect of dexmedetomidine on postoperative analgesia and sedation in pediatric patients undergoing cleft lip and palate repair. Zhonghua Yi Xue Za Zhi 2012; 92: 878-81.

27. Bellon M, Le Bot A, Michelet D, Hilly J, Maesani M, Brasher C. Efficacy of intraoperative dexmedetomidine compared with placebo for postoperative pain management: a meta-analysis of published studies. Pain Ther 2016; 5: 63-80.

28. Kim JK. An introduction to the various role of dexmedetomidine. Korean J Anesthesiol 2016; 69: 543-4.

29. Nair S, Collins M, Hung P, Rees G, Close D, Wormald PJ. The effect of beta-blocker premedication on the surgical field during endoscopic sinus surgery. Laryngoscope 2004; 114: 1042-6.

30. Mansour EE. Bis-guided evaluation of dexmedetomidine vs. midazolam as anaesthetics adjuncts in off-pump coronary artery bypass surgery (OPCAB). Saudi J Anaesth 2009; 3: 7-14. 
Appendix 1. Watcha Emergence Agitation Scale

Asleep $=0$

Calm $=1$

Crying, but can be consoled $=2$

Crying, but cannot be consoled $=3$

Agitated and thrashing around $=4$

Appendix 2. Faces, Legs, Activity, Cry and Consolability (FLACC) Behavioral Pain Assessment Scale

\begin{tabular}{lll}
\hline Parameters & \multicolumn{1}{c}{ Findings } & Points \\
\hline Face & No particular expression or smile & 0 \\
& Occasional grimace or frown, withdrawn, disinterested & 1 \\
& Frequent to constant quivering chin, clenched jaw & 2 \\
Leg & Normal position or relaxed & 0 \\
& Uneasy restless tense & 1 \\
Activity & Kicking or legs drawn up & 2 \\
& Lying quietly, normal position, moves easily & 0 \\
Cry & Squirming, shifting back and forth, tense & 1 \\
& Arched rigid or jerking & 2 \\
& Not crying (awake or asleep) & 0 \\
Consolability & Moans or whimpers; occasional complaints & 1 \\
& Crying steadily; screams or sobs; frequent complaints & 2 \\
& Content relaxed & \\
& Reassured by occasional touching hugging or being talked to, distractable & 1 \\
& Difficult to console or comfort & 2 \\
\hline
\end{tabular}

Appendix 3. Stewards Recovery Score

$\begin{array}{ll}\text { Consciousness } & 3 \\ \text { Awake } & 2 \\ \text { Response to verbal stimuli } & 1 \\ \text { Response to tactile stimuli } & 0 \\ \text { Not responding } & \\ \text { Airway } & 2 \\ \text { Cough on command or crying } & 1 \\ \text { Maintains good airway } & 0 \\ \text { Requires airway assistance } & \\ \text { Motor } & 2 \\ \text { Moves limbs purposefully } & 1 \\ \text { Non-purposeful movement } & 0 \\ \text { Not moving } & \end{array}$

